\title{
Research on the Innovation of Talent Training Mode from the Perspective of the Combination of Industry and Academic Integration
}

\author{
Siyu Peng \\ National Demonstration Center for Experimental Economics and Management Education \\ (Guangxi University of Finance and Economics), Daxuexi Road NO.189, Nanning, Guangxi, China
}

1575472078@qq.com

Keywords: Industry and academic integration, Tourism Management, Tourist Enterprises, Talent Cultivation.

\begin{abstract}
Advancing the integration of industry demands and academia while comprehensively improving the quality of personnel training have become the development trend of local undergraduate colleges and vocational colleges across the globe. This paper analyzes the shortcomings of the integration between industry demands and academic preparation in tourism management, proposes to establish a viable and feasible mechanism, develop a close-up talenttraining project for production and education, improve the training program for talents, and deepen the reform of "entering enterprises into education".
\end{abstract}

\section{Introduction}

On December 2017, the General Office of the State Council issued the "Several Opinions on Deepening the Integration of Industry and Academia" report, clarifying that "school-enterprise cooperation, cooperation and education" need to fully mobilize the enthusiasm and initiative of enterprises to participate in the integration of industry and academia, strengthen policy guidance, and encourage the attempt to promote supply and demand docking and process reengineering, and build a long-term mechanism to bridge the gap between industry requirements and academic preparation.

Chen Feng (2017), director of the School Planning and Construction Center of the Ministry of Education, pointed out: "The integration of production and education is the means, and the synergy of production and education is the result." The goal is to improve the competencies of students in terms of quality and capability. Tourism management is a very practical profession therefore, the method used to promote the integration of production and education is key to the quality of reform and innovation talents.

\section{Tourism management specialty integrated talents training mode}

The talent training model is a dynamic and static process that involves the study of cultural objects, cultures, and cultural pathways. In this model, the construction of the teaching staff and curriculum system, the reform of teaching methods, and the management system should not only be compatible with the training process, but also provide innovative thinking for the development of the process [1]. There are three main types of tourism talent training models in China, which are the combinations of "work-study integration", "integration of production, study and research" and "order-based" mode [2]. Local undergraduate colleges are generally in a transitional period. Most of the talent training models are in the primary stages of the integration of production and education. The combination of theory and skills is the main line of education, far from meeting constantly evolving market requirements. The main forms include the construction of student internship bases, post-internships, and order-based training. Enterprises play a crucial role in the teaching of talent training programs and professional development planning [3].

In local undergraduate colleges, the construction of the on-campus training room for tourism management is not paid enough attention. Hence, students' practical ability and employment 
competitiveness are reduced [2]. In terms of curriculum development and setting, the professional characteristics of the curriculum system are not prominent where it lacks standardization, profession-related practical ability and concentrated training courses. Therefore, in order to truly realize the goal of training talents for applied tourism management, local undergraduate colleges should strengthen the research on talent training mode. This needs to observe talent cultivation in industry and academic integration from the aspects of professional planning, curriculum, and training methods, internship training and other aspects of in-depth cooperation with tourism companies [5].

\section{The current situation in the cultivation of tourism management professionals integrating industry and education}

Tourism management is an applied subject. The profession requires students to have strong practical ability, especially to be familiar with future work content such as travel route design, tourist reception, tourism product creative design, emergency response handling with a flexibility in implementation [7]. Therefore, practical teaching has an irreplaceable role in theoretical teaching. The applied talents needed in the tourism industry must achieve the same supply and demand in the training process. Facing fierce market competition, tourism companies have a sense of survival and urgency. In this context, China's tourism management profession has cooperated with tourism companies to carry out different forms and degrees of integration of production and education, and achieved some results. However, due to the late start of modern tourism management education in China, the existing management system and operational mechanism of this specialty does not meet the needs of the development of industrial and academic integration due to several prominent problems:

3.1 The lack of long-term comprehensive mechanism for the integration of industrial demands and academic supply.

1) First, companies adopt risk aversion. The majority of tourism companies believe that the cooperation between universities, in production, study and research will indirectly increase the operating costs of enterprises. Wages, benefits, employee meals, and extended business hours included in the labor cost will directly or indirectly affect the increase in the operating costs of the enterprise [4]. At the same time, tourism companies are also unable to bear the safety risks of student internships, lack long-term security and planning, and are unsustainable.

2) Second, there is a shortage of school tourism management professional construction. Although schools follow industry-oriented professional construction and talent export, because the existing system has many restrictions on stakeholders in the integration of production and education, such as students, teachers, schools, enterprises, etc., it has hampered reforms. As a result, educators understanding of the industry; the number and quality of dual-teachers need to be improved; professional foresight is insufficient as well as the participation of tourism enterprises. Should you rely solely on the provision of colleges and universities without sufficient training bases on campus, most of the work scenes are on paper, resulting in a gap between students and the needs of enterprises [1].

\subsection{Integration of industry and academia remains at the level of school-enterprise cooperation.}

At present, the foundation of local undergraduate colleges in this area is insufficient. On one hand, the teaching plans, curriculum system, teaching content and practical teaching links of some tourism management professions have the tendency to weaken practical teaching though they are similar in appearance. On the surface, content is rich, but the follow-up colleges and enterprises have no relevant pursuance. In the actual operation process, it still stays at the level of "labor export" [5]. In other words, the school acquiesced to the employment mode of "employing people without employing people". This recruitment and employment separation model is a very popular employment form in the world. It solves the difficulties of employing people in tourism enterprises and the acquisition of student practice in a short period of time, but it is difficult to achieve the 
ultimate goal of "integrated education" in terms of effectiveness, cannot meet the training requirements of applied talents in tourism management. Some tourism companies also have the concept of "maximum use and minimal training" in absorbing employees from colleges and universities. They hope that new employees will have professional literacy and they can adapt quickly after entering the enterprise. Work tasks are completed, and the human, material and financial costs in the production and operation process are reduced. Instead, it ignores the recultivation of applied talents in the practice process [1].

\subsection{The integration of industry and education lacks effectiveness and continuity.}

The curriculum of the tourism management profession has certain post applicability and is in line with the needs of the industry. Therefore, some courses of the university need to be taught or conducted by professional hotel managers. However, under the integration of industry and education, undergraduate colleges have the characteristics of short cycle and irregular process.

1) First, professional managers teach at the level. As professional managers, they are not engaged in regular teaching work like full-time teachers. They will have different content and expressions in the seminars or sharing sessions, which may affect the effectiveness of the course and will further affect the students' future and their enthusiasm for tourism-related work [1].

2) Second, there are some local undergraduate colleges that have established integrated tourism and education teaching bases, such as "hotel order classes", but most of them come from temporary agreements and oral presentations. The lack of in-depth cooperation between the two sides in the optimization of the follow-up talent training model. There is no specific follow-up to jointly build a close-knit and innovative production and education integration talent training project, which is arbitrarily large, so that the effect is not satisfactory after the start of the class [4].

In general, the application-oriented talent training system with the integration of industry and academia as the main concept has not been established yet. The integration of industry and industry participation in personnel training process is insufficient. The effectiveness and sustainability of the production and education integration practice teaching base needs to be greatly enhanced.

\section{Reform Measures for Talents Training Model of Integrated Production and Education in Tourism Management}

For a long time, it has been difficult to reduce the gap between industry demands and academic preparation. The main reason is that the interests of relevant parties are not well protected, and the root cause lies in institutional constraints. Therefore, the General Office of the State Council issued the "Several Opinions on Deepening the Integration of Industry and Academia" (2017.12). According to that, the author has the following considerations for the training of tourism management professionals in local undergraduate colleges:

\subsection{Establish and improve a long-term mechanism for the integration of industry demands and academic preparation.}

Integration of production and education for students, their concerns are focused on safety and compensation. The "Opinions" clearly states "accelerate the development of student internship liability insurance and personal accident insurance, encourages insurance companies to determine the rate for modern apprenticeship and enterprise new apprenticeship insurance"; for students' internship compensation, tourism enterprises should guarantee students a reasonable compensation and other legal rights. For example, the participation of internship training in tourism management students may bring certain efficiency losses and arrange labor services generated by special personnel. For this part of the cost, it is encouraged to attract enterprises to join the school and introduce schools into enterprises to attract advantageous enterprises where the school has built and shared a productive training base. By exploring ways to purchase services and implement tax policies, enterprises are encouraged to directly receive student internship training to ensure that students enjoy legal rights such as reasonable remuneration, so as to better stimulate students' internship training initiative, and the internship training effect will continually improve. 


\subsection{Building a close-knit production and education integration talent training project.}

It is necessary to actively explore new ways of talent training mode, such as the implementation of the "enterprise order class" production and education integration talent training model, organic integration of business needs with student employment; or launch "face to face with entrepreneurs" "Enterprise Tour", special training courses, industry development forums, etc., to build a close-up production and education integration talent training project. In 2016, Guangxi University of Finance and Economics and the company's largest management consulting company, Beijing HeJun Group's HeJun Business School, reached a strategic cooperation, breaking through the shallow cooperation of traditional school enterprises "signing - issuing base signs - accepting a small number of interns". Through the introduction of the advanced teaching philosophy of HeJun Business School, first-class teachers, rich practical cases and broad resource platform, the whole process of talent cultivation is applied around the teaching methods, content and management.

Specific implementation steps:

1) First, adopt the Student Centred Learning teaching method, supplemented by online video teaching, group discussion and project-oriented teaching, and carry out real business environment teaching with local business case as the theme.

2) Second, pay attention to culture. The construction and talent literacy improvement, the establishment of "Red Management", "He Jun Culture Reader" and the introduction of the Jun business class, entrepreneurial classes and other practical courses provide significant benefits.

3) Third is the Jun business school personnel stationed in the university, participating in the class teaching organization, with both sides carrying out the whole process and all-field management of the cooperation projects, including talent training program design, enrollment, employment guidance, graduation recommendation, etc. The entire talent development process is injected into corporate culture, corporate participation and guidance.

\subsection{Improve the personnel training program \& deepen the reform of "enterprises in education".}

"Introducing enterprises into education" is a key link that closely links universities and enterprises, talent cultivation and innovation. School professional planning, textbook development, and personnel training programs all require the participation of employers. In the talent development program, the development of the curriculum is the focus because the curriculum is the core link of talent cultivation. The realization of teaching objectives, the completion of teaching tasks and the improvement of quality all depend on scientific, standardized and reasonable curriculum system. In order to change the curriculum system, it is necessary to have the participation of enterprises to develop a broad-based, live module and strong practice curriculum system [5, 6].

First, from the school to each department, a professional construction committee should be set up, specifically responsible for curriculum development. The committee needs to be composed of managers, full-time teachers and business people. It must be standardized in terms of the procedures for course development. For example, the tour guide professional course should be completed by the tour guides, enumerating the tasks to be completed in different stages such as picking up the group, taking the group, and sending the group. What skills are needed for these tasks, and the corresponding ability of each stage is taken as an example. Second, a course needs to involve the company's personnel before it is actually implemented. It accepts their tests during the teaching process, and finds the shortcomings in a timely and targeted revision to ensure the quality and consistency of the personnel training.

\subsection{Encourage superior enterprises to establish a cooperative production cooperative training base with schools.}

As a production task supply chain established by schools and cooperative enterprises, the training bases inside and outside the school not only meet the professional training and enterprise needs, but also solve the problem of high cost and high consumption of professional internships. 
School-enterprise joint construction training bases should follow the principle of joint construction and sharing, and promote a task-based training model. For example, Wenzhou University signed a contract with the Wencheng County People's Government in June to jointly build the Cultural Tourism Industry Institute and the Wenlv Industry Research Institute. The institute is set up as an independent legal entity registered by Wenzhou University in Wencheng County, and at the same time, it is also a brand of Wenzhou University [8].

As a practical practice base of Wencheng University of Science and Technology, the Institute has improved the quality of applied talents through practical practice and completion of research projects from enterprises. On the other hand, it has guided Wencheng County related enterprises to build enterprises in the Institute of Cultural Tourism. R \& D, design, operation, marketing center, etc., and do a good job in related industry services for the introduced enterprises. It is not difficult to see that in the process of integration of production and education, the use of task-based training mode will better accelerate the deep integration of universities and local industry enterprises [8].

\section{References}

[1] X. Dai: Innovative Research on Talent Cultivation Model of "Integration of Industry and Education and Integration of Industry and Education". Liaoning Journal of Higher Vocational Education, Vol. 2 (2018), p12-15. In Chinese.

[2] F. Li, S. Fang, S. Cao: Innovation Research on Tourism Talents Training in Guangxi Universities Under the New Normal. Guangxi Tourism Higher Education Research 30 Years (2015) p182. In Chinese.

[3] Y. Du, Y. Chu: Problems in the integration of production and education in local undergraduate colleges and countermeasures. Higher Education Forum, Vol. 6 (2018), p12-14. In Chinese.

[4] Z, Sheng: Research on the Integration of Industry and Education in Newly-built Undergraduate Colleges in the New Era. Contemporary Tourism Forum, Vol. 3 (2018), p25-31. In Chinese.

[5] A, Zhao: Integration of Tourism Management in the Context of Transformation and Development. Journal of Mudan Jiang Education College. Vol. 3 (2016), p68-70. In Chinese.

[6] Q, Zhou: Research on Tourism Enterprises Becoming a Talent Training Base in Tourism Colleges. Guangxi Tourism Higher Education Research 30 Years (2015), p283-286. In Chinese.

[7] N. Pang, X, Zhou: Research on the Reform of the Training Mode of Higher Vocational Tourism Professionals from the Perspective of the Combination of Production and Education. SME Management and Technology (2018), p83-84. In Chinese.

[8] Information on http://www.news.66wz.com/system/2018/06/28/105094423.shtml. In Chinese. 